\title{
Matching Research Between Engine and Transmission of Vehicle Based on AVL-Cruise
}

\author{
F. Du \\ School of Automobile and Transportation \\ Tianjin University of Technology and Education \\ Tianjin, China \\ Z.W. Guan \\ School of Automobile and Transportation \\ Tianjin University of Technology and Education \\ Tianjin, China
}

\author{
C.H. Liu \\ School of Automobile and Transportation \\ Tianjin University of Technology and Education \\ Tianjin, China \\ Y.S. Wan \\ Collage of mechanical engineering, \\ Tianjin University of Technology and Education \\ Tianjin, China
}

\begin{abstract}
Using the analysis of the design goals for a new car, the basic structure type of this new car was determined. Under the presupposition of giving power unit, the various of matching scheme of driveline and engine was selected preliminary. The vehicle model was construced by using AVL-Cruise software, and the performance simulation and theory analysis were carried out for the different combination of the power plant and driveline, the optimum matching of powertrain to meet the performance required was chosed in the eventually. Practice has proved that the development cycle of new car can be shortened, the research and development costs can be reduced by using the simulation platform of AVL-Cruise software.
\end{abstract}

Keywords-optimization matching; power; driveline; cruise simulation

\section{INTRODUCTION}

The development of automobile industry so far, the requirement and the expectation to all aspects of vehicle performance is more stringent and higher, how to improve the vehicle performance has become one important subject[1]. The whole performance of vehicle depends not only on the quality of each assembly and component, but also on the parameters matching among the different as semblies one another. Usually, the assessment to the dynamics, economy and emission of vehicle depends on whether it is reasonable that matching between engine and dynamic system to a great degree, matching scheme between the engine and drive train may have a variety of programs, if all program must have real test, the development costs of new product will be increased, the design cycle will be extended, therefore, it is necessary to do the work of the power matching and performance analysis in the design phase of new product, namely there is no experimental prototype case[2]. In view of this situation, some car companies tried to predict the car performance, and study the optimum matching of power plant with driveline by using computer simulation techniques in the early stages of the design, and had achieved good effect[3]. This approach helps the R\& D department to identify design scheme quickly, not only improving the performance of new products, but also shortening the development cycle and saving the development cost, so it has been paid more and more attention to production enterprises.

At present, on the premise of the test for typical driving cycle of car, the major car companies or research institutions have developed their own car simulation programs, these simulation programs are used to simulate the power and economy performance of car, and to find the matching parameters of meeting the design requirements. Such as Austria AVL Company, it provides specially advice and technical support for the automotive power train design or manufacturing company, the CRUISE software developed by A VLCompany can carry out some simulation research for power, fuel economy, emissions and braking performance of automotive, and so on[4]. The simulation platform has been successful build up a bridge between the manufacturers and parts suppliers, through its convenient general model element, intuitive data management system and modeling processes and software interfaces based on the engineering application. With the increasingly strict emission regulation and the fuel shortage, the regulations to emissions and economy of car in many countries are becoming more and more stringent; the cruise simulation software will also promote the use of more.

In this paper, a newly developed medium-sized sedan is studied with simulation technology by using Cruise software, its purpose is to find the optimum matching of driveline parameter from the different types of transmis sions and final drives, to give full play the power performance of vehicle while taking into account the economy.

\section{SELECTION OF ENGINE POWER}

During the development process of vehicle, the design scheme of the power driveline is often a kind of combination matching among the mature engine on the market, transmission 
and main reducer under the premise of design tasks identified. Based on the requirements of dynamic performance and fuel economy, the power plant parameters of vehicle were selected in accordance with the following conditions or design experience[5].

\section{A. Power Selection Using the Expectant top Speed}

The higher the top speed, the lager the engine power required, so the greater the back-up power of vehicle, the better necessarily the acceleration and grade ability. So, although the maximumspeed is only one of the power index, but it also reflects the acceleration and grade ability of vehicles in essence. Therefore, it often preliminarily selects a proper engine power to ensure the expectant top speed in a design. Namely, the engine power should be approximately equal to or slightly greater than the sum of the driving resistance power when traveling at maximum speed.

$$
P_{e}=\frac{1}{\eta_{T}}\left(\frac{G f}{3600} u_{a \max }+\frac{C_{D} A}{76140} u_{a \max }^{3}\right)
$$

In the above formula, $\mathrm{Pe}$ is the engine power, $\eta \mathrm{T}$ is the transmission efficiency, $G$ is the total vehicle weight, $f$ is the rolling res is tance coefficient, uamax is the maximum speed, $\mathrm{CD}$ is the air resistance coefficient, $\mathrm{A}$ is the car windward area.

\section{B. Power Determination Using the Specific Power of Vehicle}

Specific power of vehicle refers to the engine power of the unit total mass. The specific power of different countries and different types of automobiles (such as car and truck) are located in a statistical region, this area represents the overall level of vehicle design and manufacture. Therefore, in practical work, the engine power can be selected preliminarily according to the statistical data of specific power of some vehicles that have the same total mass or the same type.

$$
P=\frac{1000 P_{e}}{m}=\frac{f g}{3.6 \eta_{T}} u_{a \max }+\frac{C_{D} A}{76.14 m \eta_{T}} u_{a \max }^{3}
$$

In the above formula, $\mathrm{P}$ is the vehicle specific power, $\mathrm{m}$ is the vehicle total mas $s, \mathrm{~g}$ is the acceleration of gravity.

\section{PARAMETER SELECTION OF TRANSMISSION DEVICE}

\section{A. Selection of the Gear Number and Speed Ratio of Each Gear}

Theoretically, the more the number of transmission gear, the better the power and economy performance of the vehicle, but the gear number are subject to maximum, minimum speed ratio and the ratios between the every gear. If the ratios are too large, it will cause a difficult shift, so this ratio must not exceed 1.7-1.8 generally.
Usually, each gear ratio of transmission is distributed according to the geometric progression, that is, the ratio between the two adjacent gears is a constant value. But in practice, considering the economy requirement and the application frequency of each gear (car is often traveling with a higher range mainly), owing to utilization rate of each gear exists great difference, so the ratio interval between the adjacent higher gears should be smaller, each gear ratio of transmission is often allocated according to the following relationship.

$$
\frac{i_{g 1}}{i_{g 2}} \geq \frac{i_{g 2}}{i_{g 3}} \geq \cdots \geq \frac{i_{g n-1}}{i_{g n}}
$$

In the above formula, $i_{g 1}, i_{g 2}, \ldots, i_{g n}$ is gear ratio, respectively.

\section{B. Selection of Gear ratio for Transmission}

When determining the maximum gear ratio of transmission (first gear), the maximum grade ability should be considered firstly, if necessary, the checking computations should be done to attachment rate, the lowest stable speed is also the one of the factors that should be considered for off-road vehicle. Usually, the ratio for first gear of transmission should meet the following conditions.

$$
i_{g 1} \geq \frac{G\left(f \cos \alpha_{\max }+\sin \alpha_{\max }\right) r}{T_{t q \max } i_{0} \eta_{T}}
$$

In the above formula, $\alpha$ max is the maximum slope angle, $r$ is the wheel rolling radiu, Ttqmax is the Maximum engine torque, i0 is the final drive ratio.

\section{Selection of Gear Ratio for Final Drive}

Under the condition of preliminary defining maximum engine power and its corresponding speed, the gear ratio of final drive chosen should be to ensure that the car has top speed as high as possible, which should meet the following conditions:

$$
i_{0}=0.377 \frac{r \cdot n_{p}}{i_{p} \cdot u_{a \max }}
$$

In the formula, $\mathrm{np}$ is the engine speed corresponding to peak-power; ip is the top gear ratio of transmission.

\section{MODELING AND SimUlation ANALYSIS OF VEHIClE PERFORMANCE USING CRUISE}

This research object is a pre-precursor midsize sedan, the type of engine and vehicle-related parameters have been determined, See Table 1.

In order to obtain a reasonable power and economy, the two kinds of 5-speed manual transmission (Each speed ratio is 
different, see Table 2) and the three kinds of main reducer (Ratio $\mathrm{i} 0$ is $2.85,3$ and 3.75 , respectively) was selected to match for this engine, the six kinds of driveline combinations was formed eventually, and each gear ratio and the final ratio was calculated and determined in accordance with the aforementioned theory. The following main work of this study is to build such a vehicle model by using the Cruise software, and select the optimum match from these six kinds of combinations through simulation and analys is subsequently.

Figure 1 is the vehicle model established by using Cruise software finally, the modeling process can be referred in the related literature[6]. Through setting computing tasks and matrix simulation procedure, each simulation results of the performance can be obtained and shown in Table 3. Figure 2 and Figure 3 are two kinds of instance of the performance curves by simulating.

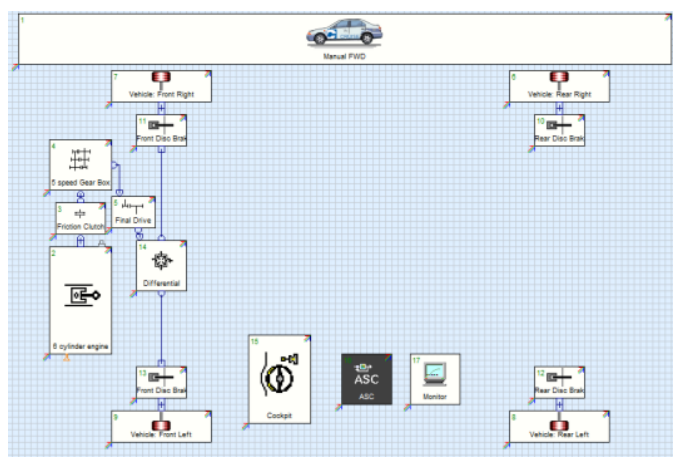

FIGURE I. MANUAL FRONT-WHEEL DRIVE MIDSIZE SEDAN MODEL BY USING CRUISE.

As can be seen from table 3, if we only pursue the power performance of vehicle, then the driveline matching of A-3.75 and B-3.75 are relatively satisfactory. If we hope the maximum speed, the ability of overtaking acceleration (top gear, from $60 \mathrm{~km} / \mathrm{h}$ to $140 \mathrm{~km} / \mathrm{h}$ ) and climbing grade of car are all stronger, then selecting the A-3.75 of combination; if we hope the ability of starting and acceleration (from 0 to top speed), overtaking and climbing are good, then selecting the B-3.75 of combination. If only from the pers pective of economic terms, there is almost no difference in fuel consumption of constant speed driving at three speed, if referring fuel consumption of driving cycle further, then the B-2.85 of combination is the most ideal. If both the power and economy must be taken into account, that is in the premise of ensuring power, while having the better economy as far as possible, then fromthe A-3.75 and B-3.75 two kinds of matching, only choosing the combination of B-3.75. Through the above analysis we can see, In pursuit of the goal of different design, the simulation calculation using CRUISE can provide technical and data support for designers according to the different design goal If recombining the professional knowledge to analyze the forming factors of all data, it will deepen the understanding to theory and enhance the design experience in engineering.

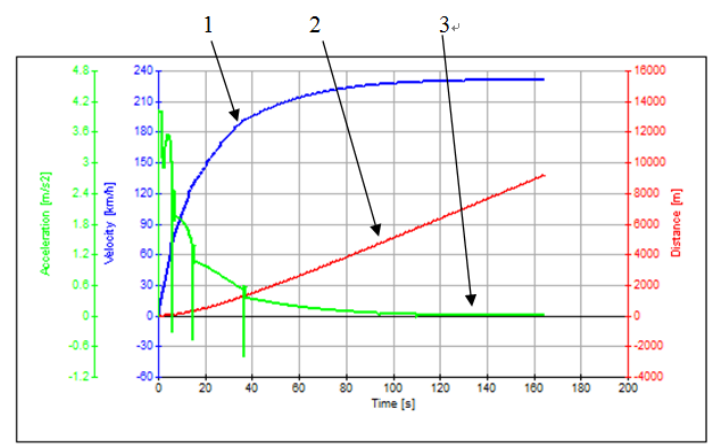

(1: Speed-time; 2: Displacement - time; 3: Acceleration - time) FIGURE II. ACCELERAT ION CURVE OF CONT INUUOUS SHIFT FROM ST ANDING ST ART.

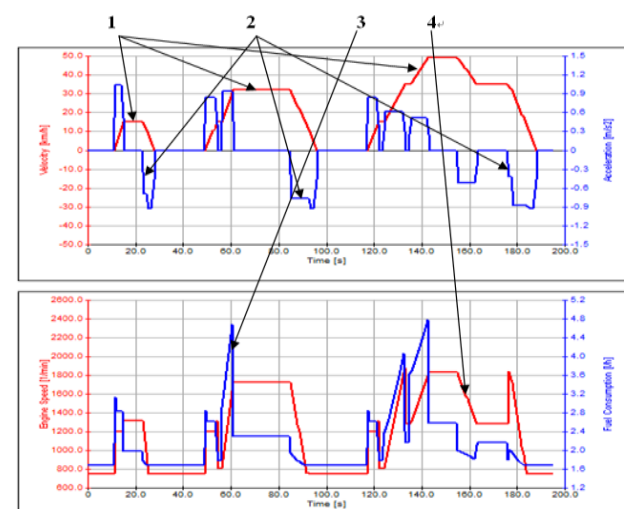

(1: Speed-time; 2: Acceleration - time 3: Fuel consumption - time; 4: Engine rotational speed - time)

FIGURE III. FUEL CONSUMPTION CURVE OF DRIVING CYCLE.

T ABLEI. PARAMETERS OF VEHICLE AND ENGINE.

\begin{tabular}{|c|c|c|c|}
\hline Item & Vehicle parameter & Item & Engine parameters \\
\hline Total mass / Curb Weight, $(\mathrm{kg})$ & $1930 / 1450$ & Engine Type & $\begin{array}{l}\text { Water-cooled } 4 \text {-stroke naturally } \\
\text { aspirate }\end{array}$ \\
\hline Length $\times$ width $\times$ height,$(\mathrm{mm})$ & $4650 \times 1750 \times 1505$ & Engine displacement, $(L)$ & 2.478 \\
\hline Wheelbase, $(\mathrm{mm})$ & 2650 & Number of cylinders & 6 \\
\hline Tread (front/rear), $(\mathrm{mm})$ & $1627 / 1618$ & Maximum power, $(\mathrm{kW} / \mathrm{r} / \mathrm{min})$ & $127 / 6000$ \\
\hline Drive form & Front-wheel drive & Maximum torque, (N.m) & 175 \\
\hline
\end{tabular}

T ABLEII. WO KINDS OF GEAR RAT IO SCHEMES OF MANUAL TRANSMISSION.

\begin{tabular}{c|c|c|c|c|c}
\hline Shift & $1^{\text {st }}$ gear & $2^{\text {nd }}$ gear & $3^{\text {rd }}$ gear & $4^{\text {th }}$ gear & $5^{\text {th }}$ gear \\
\hline Scheme A & 3.62 & 2.22 & 1.51 & 1.08 & 0.85 \\
\hline Scheme B & 3.46 & 1.94 & 1.29 & 0.97 & 0.8 \\
\hline
\end{tabular}


T ABLEIII. SIMULATION RESULTS OF VEHICLE PERFORMANCE BY USING CRUISE.

\begin{tabular}{|c|c|c|c|c|c|c|c|c|}
\hline \multirow{2}{*}{ Index } & \multirow{2}{*}{$\begin{array}{c}\text { Top speed, } \\
(\mathrm{km} / \mathrm{h})\end{array}$} & \multirow{2}{*}{$\begin{array}{c}\text { Grade-ability, } \\
(\%)\end{array}$} & \multicolumn{2}{|c|}{ Acceleration time, (s) } & \multicolumn{3}{|c|}{$\begin{array}{l}\text { Fuel consumption with constant speed, } \\
(\mathrm{L} / 100 \mathrm{~km})\end{array}$} & \multirow{2}{*}{$\begin{array}{c}\text { Cycling fuel } \\
\text { consumption } \\
(\mathrm{L} / 100 \mathrm{~km})\end{array}$} \\
\hline & & & $0 \rightarrow v_{\max }$ & $60 \rightarrow 140 \mathrm{~km} / \mathrm{h}$ & $60 \mathrm{~km} / \mathrm{h}$ & $90 \mathrm{~km} / \mathrm{h}$ & $120 \mathrm{~km} / \mathrm{h}$ & \\
\hline $\mathrm{A}-2.85$ & 229.28 & 46 & 90 & 50 & 4.2 & 4.2 & 5.0 & 12.97 \\
\hline A-3 & 226.84 & 49 & 80 & 45 & 4.2 & 4.2 & 5.2 & 13.12 \\
\hline $\mathrm{A}-3.75$ & 231.50 & 55 & 110 & 38 & 4.3 & 4.2 & 5.5 & 14.22 \\
\hline B-2.85 & 231.53 & 43 & 105 & 57 & 4.1 & 4.2 & 5.0 & 12.04 \\
\hline B-3 & 232.50 & 46 & 103 & 51 & 4.1 & 4.1 & 5.0 & 12.55 \\
\hline B-3.75 & 228.31 & 52 & 70 & 43 & 4.2 & 4.2 & 5.1 & 13.57 \\
\hline
\end{tabular}

\section{$\mathrm{V}$ CONCLUSION}

In this paper, the vehicle modeling and performance simulation were applied to match driveline system of a mid-size sedan by using AVL-Cruise software, the optimum matching scheme of this car power-train was obtained by analyzing the calculation results, this scheme can further improve the economy of the vehicle on the premise of ensuring good dynamics. Research shows that the optimum matching of driveline and engine is able to quickly and easily implement by using simulation function of Cruise software, this technology can predict vehicle performance, shorten the development cycle, and reduce $\mathrm{R} \& \mathrm{D}$ costs in early development.

\section{ACKNOWLEDGMENT}

The authors gratefully acknowledge the National Natural Science Foundation of China (No.51105131) and the Key Project of Tianjin Research Program of Application Foundation and Advanced Technology (No.12JCZDJC34500) for financial support of this research work.

\section{REFERENCE}

[1] LIU Wei-xin, GE Ping, LI Wei. Study of optimal matching between automobile engine and transmission parameters. Automotive Engineering, 1991, 13(2): 65-72.

[2] YANG Lian-sheng. The optimal matching between internal combustion en gine performance and transmission. Beijing, Academic Periodical Press, 1988: 12-26.

[3] XIAO Ming-wei, YANG Jing. Study on the Matching between 495QME engine and CDK6710 carriage transmission system. Hunan University. Institute of Machinery and Automotive Engineering, 2006: 50-55.

[4] LIU Zhen-jun, ZHAO Hai-feng, QIN Da-tong. Simulation and analysis of vehicle powertrain based on CRUISE. Journal of Chongqing University (Natural Science), 2005, 28(11): 8-11.

[5] LIU Qing-quan. Design \& matching for city vehicle and engine. Jilin University. Institute of Automotive Engineering, 2004: 35-37.

[6] Shen Ailing, Fu Jun, Zhang Yanfa. Matching simulation and driveline optimization for CA7204 passenger car. Journal of Central South University (Natural Science), 2011, 42 (3): 677-681. 